\title{
Type and composition of surfactants mediating gene transfection of polyethylenimine-coated liposomes
}

Praneet Opanasopit ${ }^{1}$ Orapan Paecharoenchai' Theerasak Rojanarata' Tanasait Ngawhirunpat' Uracha Ruktanonchai ${ }^{2}$

'Faculty of Pharmacy, Silpakorn University, Nakhon Pathom, ${ }^{2}$ National Nanotechnology Center, Thailand Science Park, Pathumthani, Thailand
Correspondence: Praneet Opanasopit Faculty of Pharmacy, Silpakorn University, Nakhonpathom, 73000, Thailand

Tel +6634255800

Fax +66 3425580 I

Email praneet@su.ac.th
This article was published in the following Dove Press journal:

International Journal of Nanomedicine

9 May 2011

Number of times this article has been viewed

Background: The objective of this study was to compare the transfection efficiency of anionic liposomes coated with polyethylenimine (PEI) with that of PEI and Lipofectamine $2000^{\mathrm{TM}} \mathrm{using}$ the plasmid DNA encoding green fluorescent protein in a human hepatoma (Huh7) cell line.

Methods: Factors affecting transfection efficiency, including type of surfactant, ratio of phosphatidylcholine (PC)/surfactant, carrier/DNA weight ratio, and the presence of serum have been investigated. Anionic liposomes, composed of PC and anionic surfactants, ie, sodium oleate $(\mathrm{NaO})$, sodium taurocholate $(\mathrm{NaT})$, or zwitterionic surfactant (3-[\{3-cholamidopropyl $\}$ dimethylammonio]-1-propanesulfonate, CHAPS) at molar ratios of 10:1, 10:1.5, and 10:2 were prepared by the sonication method. Subsequently, they were coated with PEI to produce polycationic liposomes (PCL).

Results: PCL was able to condense with pDNA depending on the PCL/DNA weight ratio. PCL composed of PC: $\mathrm{NaO}$ (10:2) showed higher transfection efficiency than NaT and CHAPS at all weight ratios tested. Higher transfection efficiency and gene expression were observed when the carrier/DNA weight ratio increased. The highest transfection efficiency was found at a weight ratio of 0.5 .

Conclusion: This PCL showed remarkably high transfection efficiency with low cytotoxicity to Huh7 cells in vitro, in comparison with PEI and Lipofectamine 2000.

Keywords: polycation liposomes, polyethylenimine, gene delivery, transfection efficiency

\section{Introduction}

Gene delivery has been regarded as a powerful tool for curing disease by replacing defective genes, substituting missing genes, or silencing unwanted gene expression. The two main types of vectors used in gene therapy are viral and nonviral vectors. Among the nonviral vectors, cationic liposomes ${ }^{1-3}$ and polycations ${ }^{4,5}$ have been widely investigated. Cationic liposomes form a complex with anionic DNA molecules and are thought to deliver DNA through the endosomal pathway. ${ }^{6}$ The precise mechanism for gene transfection mediated by cationic liposomes is still unclear. However, fusion with the endosomal membrane or destabilization of the membrane by cationic liposomes may trigger the effective cytosolic delivery of DNA. ${ }^{7,8}$ However, the cationic liposomal system has some disadvantages, such as low efficiency of transfection, due to DNA degradation in lysosomes, and strong cytotoxicity. ${ }^{9}$ On the other hand, polycations, such as polyethylenimine (PEI), also form a complex with anionic DNA molecules and are taken up into target cells via the endosomal pathway. However, in the case of polycations, unlike cationic liposomes, the DNA released into the cytoplasm from 
endosomes, due to the proton-sponge effect of PEI, may further be delivered to the nucleus by the polycation. ${ }^{10,11}$

Yamazaki et $\mathrm{al}^{12,13}$ prepared polycation liposomes (PCL) by modification of a liposome with cetyl PEI, and found that PCL could actually deliver genes effectively in the presence of serum and in vivo with low cytotoxicity. The mechanism for effective gene transfer by PCL was that PCL transfer DNA to endosomes and release cetyl PEI/DNA complexes into the cytosol. Furthermore, cetyl PEI also contributes to gene entry into the nucleus. ${ }^{14}$ Chen et $\mathrm{al}^{15}$ also prepared PCL using PEI (molecular weight 800) and cholesterol. These PCL had transfection efficiency equivalent to that of Lipofectamine $2000^{\mathrm{TM}}$ with significantly low cytotoxicity. In general, the key step of gene delivery is thought to be not the delivery of DNA into the cytosol through the endosomal pathway but rather the entry of cytosolic DNA into the nucleus when cationic liposomes are used as a nonviral vector. ${ }^{16}$ Therefore, gene delivery is cell-cycle dependent, and effective gene delivery is achieved only in dividing cells. If PEI has the ability to enter into the nucleus in nondividing cells, then PCL may have the dual advantage of both cationic liposomes for cytosolic delivery of DNA and polycations for delivery of cytosolic DNA into the nucleus. Alternatively, if PEI cannot pass through the nuclear membrane, it still has the ability to enhance interaction of foreign DNA with chromatins during cell division.

Although many researchers have attempted to develop an effective nonviral gene transfer system by combination of both cationic liposomes and polycations as an alternative gene carrier, few have been successful in increasing transfection efficiency. Lampela et al have reported that the use of PEI cationic liposomes (Dosper) for nonviral gene delivery showed synergism between cationic lipid Dosper and small molecular weight PEI in transfection. ${ }^{17}$ They suggested that this synergism was based on two independent mechanisms, ie, the liposome improves cellular uptake of PEI/DNA complexes, and PEI improves the transfer of the complexes from the lysosomes to the nucleus. They found that high molecular weight PEI with linear (PEI $22 \mathrm{~K}$ ) and branched (PEI $25 \mathrm{~K}$ ) structures in combination with Dosper liposomes could be used to increase the efficiency of gene delivery in vitro. ${ }^{18}$ Moreover, they combined low molecular weight PEI (MW 700 and 2000) with Superfect (a dendrimer) and two liposomes, ie, Dotap (N-[1-\{2,3-dioleoyloxy\}propyl]-N,N,Ntrimethylammonium methylsulfate) and Lipofectamine. The highest synergism was achieved with Lipofectamine and PEI in Rabbit smooth muscle (SMC) cells, or with Dotap and PEIs in rat glioma (C6) cells. Superfect did not induce any synergism. ${ }^{19}$ Therefore, in this study, PEI-coated liposomes with different compositions were prepared to investigate the physicochemical properties intended for gene delivery. Surfactants, ie, (3-[\{3-Cholamidopropyl\} dimethylammonio]-1-propanesulfonate, CHAPS), sodium taurocholate $(\mathrm{NaT})$, or sodium oleate $(\mathrm{NaO})$ was added to phosphatidylcholine (PC) to form an anionic liposome. A number of variables influencing transfection efficiency, such as carrier/DNA weight ratio, type of surfactants (CHAPS, $\mathrm{NaT}$ and $\mathrm{NaO}$ ), particle size, zeta potential, morphology, and serum were investigated. In vitro gene transfection assay was performed with a human hepatoma (Huh7) cell line using plasmid DNA encoding green fluorescent protein (pEGFP-C2). Evaluation of cytotoxicity was performed by the MTT assay. The results revealed that PEI-coated anionic liposomes $\mathrm{PC}: \mathrm{NaO}$ (10:2) showed high transfection efficiency with low cytotoxicity to $\mathrm{Huh} 7$ cells in vitro, in comparison with PEI and Lipofectamine 2000.

\section{Material and methods Materials}

Egg yolk PC was purchased from Wako Pure Chemical (Osaka, Japan). Branched PEI, (molecular weight $25 \mathrm{kDa}$, 3-[\{3-Cholamidopropyl $\}$ dimethyl ammonio]-1-propanesulfonate, CHAPS), sodium oleate $(\mathrm{NaO})$, and sodium taurocholate (NaT), Tris, Triton-X 100, and 3-(4,5-dimethylth iazol-2-yl)-2,5-diphenyl tetrazolium bromide (MTT) were purchased from Sigma Chemical Co (St Louis, MO). Dulbecco's modified Eagle's medium (DMEM), trypsin-ethylenediamine tetra-acetic acid (EDTA), penicillin-streptomycin antibiotics, fetal bovine serum, and Lipofectamine 2000 were obtained from Gibco Invitrogen (Grand Island, NY). pEGFP-C2 was obtained from Clontech (Palo Alto, CA). The $\lambda$ DNA/HindIII marker was obtained from Promega (Madison, WI). Human hepatocellular carcinoma (Huh7) cells were obtained from the American Type Culture Collection (Rockville, MD). All other chemicals were of cell culture and molecular biology quality.

\section{Plasmid preparation}

pEGFP-C2 was propagated in Escherichia coli DH5- $\alpha$ and purified using the Qiagen endotoxin-free plasmid purification kit (Qiagen, Santa Clarita, CA). DNA concentration was quantified by the measurement of ultraviolet absorbance at $260 \mathrm{~nm}$ using a GeneRay ultraviolet photometer (Biometra $^{\circledR}$, Goettingen, Germany). The purity of the plasmid was verified by gel electrophoresis $(0.8 \%$ agarose gel $)$ in Tris acetate-EDTA buffer, $\mathrm{pH} 8.0$, and using $\lambda$ DNA/HindIII as a DNA marker. 


\section{Preparation of PEl-coated liposomes}

Different formulations composed of a bilayer forming PC, in combination of $\mathrm{NaO}, \mathrm{CHAPS}$, or $\mathrm{NaT}$, in molar ratios of 10:1, 10:1.5, and 10:2, were prepared by the sonication method. Briefly, PC, CHAPS, $\mathrm{NaO}$, and $\mathrm{NaT}$ were separately dissolved in chloroform:methanol $(2: 1 \mathrm{v} / \mathrm{v})$. The materials were deposited in a test tube and the solvents were evaporated under nitrogen gas flow. The lipid film was placed in a desiccator connected to a vacuum pump for six hours to remove remaining organic solvents. The dried lipid film was hydrated with Tris buffer ( $20 \mathrm{mM}$ Tris and $150 \mathrm{mM} \mathrm{NaCl}, \mathrm{pH}$ 7.4). Following hydration, the dispersion was sonicated in a bath sonicator for 10 minutes and then in a probe sonicator, each for 30 minutes in two cycles. For PEI-coated liposomes, the liposomes were mixed with PEI solution $(1 \mathrm{mg} / \mathrm{mL})$ at the ratio of $1: 1(\mathrm{w} / \mathrm{w})$ with a magnetic stirrer for 30 minutes.

\section{Preparation and characterization of PCL/DNA complexes}

The PCL/DNA complexes were prepared at various carrier/ DNA weight ratios by adding DNA solution to the PCL solution. The mixture was gently mixed using a pipette for 3-5 seconds to initiate complex formation and was left for 15 minutes at room temperature. The complex formation was confirmed by electrophoresis. Agarose gels were prepared with $1 \%$ agarose solution in Tris acetate-EDTA buffer with ethidium bromide $0.5 \mu \mathrm{g} / \mathrm{mL}$. The electrophoresis was carried out for 60 minutes at $100 \mathrm{~V}$. The volume of the sample loaded in the well was $15 \mu \mathrm{L}$ of PCL/DNA complex containing $1 \mu \mathrm{g}$ of DNA.

\section{Size and zeta potential measurements}

The particle size and surface charge of the PCL/DNA complexes were determined by photon correlation spectroscopy using the Zetasizer Nano ZS (Malvern Instruments Ltd, Malvern, UK) at room temperature. The complexes were diluted with distilled water which was previously passed through a $0.22 \mu \mathrm{m}$ membrane filter. All samples were measured in triplicate.

\section{Morphology}

The morphology of the PCL/DNA complexes was analyzed by transmission electron microscopy and atomic force microscopy. Analyzed by transmission electron microscopy, $3 \%$ solution of Formvar was prepared in spectroscopic-grade chloroform. Then, one drop of the sample solution of PCL/ DNA complex was put on a Formvar-coated carbon ultrathin grid and air-dried. The dried grid was then examined by transmission electron microscopy (JEOL JEM1230, Tokyo, Japan). Analyzed by atomic force microscopy (SPA400, Seiko, Japan), appropriate amounts of PCL/DNA complexes were diluted with water and deposited onto a freshly cleaved mica substrate. Samples were imaged after evaporation to dryness by scanning a $5000 \mathrm{~nm} \times 1000 \mathrm{~nm}$ area in tapping mode using a NSG 10 cantilever with $190-325 \mathrm{kHz}$ resonance frequencies and a constant force in the range of $5.5-22.5 \mathrm{~N} / \mathrm{m}$. The images were recorded in air at room temperature and a scan speed of $1 \mathrm{~Hz}$, and the phase image and topology were used to determine the morphology and particle size of the liposomes.

\section{In vitro transfection PCL/DNA complexes in Huh7 cells}

Huh7 cells were seeded into 24-well plates at a density of $5 \times 10^{4}$ cells $/ \mathrm{cm}^{2}$ in $1 \mathrm{~mL}$ of growth medium (DMEM containing $10 \%$ fetal bovine serum, supplemented with $2 \mathrm{mM}$ L-glutamine, 1\% nonessential amino acid solution, $100 \mathrm{U} / \mathrm{mL}$ penicillin, and $100 \mu \mathrm{g} / \mathrm{mL}$ streptomycin). The cells were grown in a humidified atmosphere $\left(5 \% \mathrm{CO}_{2}, 95 \%\right.$ air, $37^{\circ} \mathrm{C}$ ) for 24 hours. Prior to transfection, the medium was removed and the cells were rinsed with phosphate-buffered saline ( $\mathrm{pH}$ 7.4). The cells were incubated with $0.5 \mathrm{~mL}$ of the $\mathrm{PCL} / \mathrm{DNA}$ complexes at various weight ratios containing $1 \mu \mathrm{g}$ of pDNA for 24 hours at $37^{\circ} \mathrm{C}$ in a $5 \% \mathrm{CO}_{2}$ atmosphere. Nontreated cells and cells transfected with naked plasmid, PEI/DNA complexes, and Lipofectamine 2000/DNA complexes were used as controls. After transfection, the cells were washed twice with phosphate-buffered saline and grown in culture medium for 24 hours to allow for green fluorescent protein expression. All transfection experiments were performed in triplicate.

\section{Evaluation of cell viability}

Evaluation of cytotoxicity was performed by the MTT assay. Huh7 cells were seeded in a 96-well plate at a density of $5 \times 10^{4}$ cells $/ \mathrm{cm}^{2}$ in $200 \mu \mathrm{L}$ of growth medium and incubated for 24 hours at $37^{\circ} \mathrm{C}$ in a $5 \% \mathrm{CO}_{2}$ atmosphere. Prior to evaluation of cytotoxicity, the medium was removed and the cells were rinsed with phosphate-buffered saline. They were supplied with the PCL/DNA complexes in the same concentrations as for the in vitro transfection experiment. After treatment, the PCL/DNA complex solutions were removed. Finally, the cells were incubated with $100 \mu \mathrm{L}$ MTT-containing medium $(1 \mathrm{mg} / \mathrm{mL})$ for four hours. Then the medium was removed, the cells were rinsed with phosphatebuffered saline (pH 7.4), and formazan crystals formed in 
living cells were dissolved in $100 \mu \mathrm{L}$ dimethyl sulfoxide per well. Relative viability (\%) was calculated based on absorbance at $550 \mathrm{~nm}$ using a microplate reader (Universal Microplate Analyzer, Models AOPUS01 and AI53601, Packard BioScience, East Lyme, CT). The viability of nontreated control cells was arbitrarily defined as $100 \%$.

\section{Statistical analysis}

The statistical significance of differences in transfection efficiency and cell viability were examined using one-way analysis of variance followed by a least-squares difference post hoc test. The significance level was set at $P<0.05$.

\section{Results and discussion}

\section{Characterization of PCL/DNA complexes}

In order to determine the optimal complexation conditions, it was necessary to evaluate the degree of binding between either PEI or PCL and DNA at different carrier concentrations. The formation of complexes between PCL and the pEGFP-C2 plasmid DNA was visualized by agarose gel electrophoresis. By varying the concentration of PCL and fixing the DNA concentration, the weight ratios of the particle formulations were varied (Figure 1; Lane 1, pEGFP-C2 plasmid; lanes 2-7, PCL/DNA complexes with weight ratios of $0.05,0.1,0.5$, 1, 5, and 10). As shown in Figure 1, PCL/DNA complexes showed different gene condensation patterns. In the case of $\mathrm{PC} / \mathrm{NaO}$ liposomes (Figure 1A-C), complete complexes were formed at carrier/DNA weight ratios above 0.05 in all $\mathrm{PC} / \mathrm{NaO}$ ratios $(10: 1,10: 1.5$, and 10:2). On the other hand, PC/CHAPS (Figure 1D-F) and PC/NaT (Figure 1G-I) formed complete complexes with DNA at carrier/DNA weight ratios above $0.1,0.05$, and 0.05 for PC/CHAPS and $\mathrm{PC} / \mathrm{NaT}$ at ratios of $10: 1,10: 1.5$, and 10.2 , respectively. These results revealed that the $\mathrm{NaO}$ had a stronger binding ability to DNA than that of CHAPS and NaT.

Particle size and the zeta potential were plotted against weight ratios of PEI/DNA complexes (Figure 2A) and PCL/DNA complexes formulated with PEI-coated PC/NaO (10:2) liposomes (Figure 2B), PEI-coated PC/CHAPS (10:2) liposomes (Figure 2C), and PEI-coated PC/NaT (10:2) liposomes (Figure 2D). The particle sizes of the PEI/DNA complexes were in the $200-500 \mathrm{~nm}$ range (PDI 0.21-0.64) after a weight ratio of 0.75 (Figure $2 \mathrm{~A}$ ). The particle sizes of PLC formulated from $\mathrm{PC} / \mathrm{NaO}$ and PC/CHAPS liposomes were slightly larger than the PEI/DNA complexes, whereas PLC formulated from PC/NaT showed the largest particle size (550-1595 nm). An initial negative value of the zeta potential was observed for all anionic liposomes $(\mathrm{PC} / \mathrm{NaO}$,
PC/CHAPS, and PC/NaT). On the other hand, PEI-coated liposomes at 1:1 (w/w) showed positive values for the zeta potential. The zeta potential of all the PCL/DNA complexes was found to increase with increasing weight ratios of PCL, due to their higher density of protonated amines in the PCL. A similar result was observed in PEI (Figure 2A). Morphological examination of the PEI-coated PC/NaO (10:2) liposome/DNA complexes at a weight ratio of 0.5 were performed by transmission electron microscopy and atomic force microscopy. The images revealed that the complexes were spherical and nanosized (Figure 3).

\section{In vitro transfection}

Achievement of high gene transfection efficiency is the final goal for the development of novel gene carriers. To investigate PCL-mediated gene transfection efficiency, an in vitro gene transfection assay was performed with a human hepatoma (Huh7) cell line using pEGFP-C2. PCL formulated with three kinds of anionic liposomes (PC/NaO, PC/CHAPS, and $\mathrm{PC} / \mathrm{NaT}$ at molar ratios of 10:1, 10:1.5, and 10:2, respectively) and then coated with PEI at a weight ratio of $1: 1$. In order to investigate the optimal conditions for gene transfection, the PCL were complexed with DNA at various weight ratios of $0.3,0.4,0.5,0.75,0.9,1.0$, and 1.5. PEI and Lipofectamine 2000 complexed with DNA at weight ratios of 1 and 2, respectively, were used as a positive control. In all studies, there were no transfection in controls (cells without complexes) and naked DNA. As shown in Figure 4 (at pH 7.4), the gene transfection efficiencies were significantly influenced by the carrier/DNA ratio and the type and ratio of surfactants used in the liposome formulation. For PC/NaO (Figure 4A-C) and PC/CHAPS (Figure 4D-F), by increasing the molar ratio of surfactant (from 10:1 to 10:2), the transfection efficiencies increased, and the highest values were observed at the molar ratio of 10:2, whereas the highest values of transfection efficiencies of $\mathrm{PC} / \mathrm{NaT}$ (Figure 4G-I) were at the molar ratio of 10:1.5. In all PCL, the gene transfection efficiencies were significantly influenced by the carrier/DNA ratio. By increasing the ratios, the transfection efficiencies reached the highest values with a decrease by further increment of the ratios. Among the carriers, PEI-coated PC/NaO (10:2) showed the highest transfection efficiency (Figure 4C). Some PCL formulations were much more effective in gene transfer than conventional polyplexes of PEI. PCL containing PC/NaO (10:2, carrier/DNA weight ratio 0.5) showed five times higher gene expression than the polyplex prepared with the same polymer of PEI (Figure 5A). These results suggest that PCL may have the dual advantages of being both liposomes for 

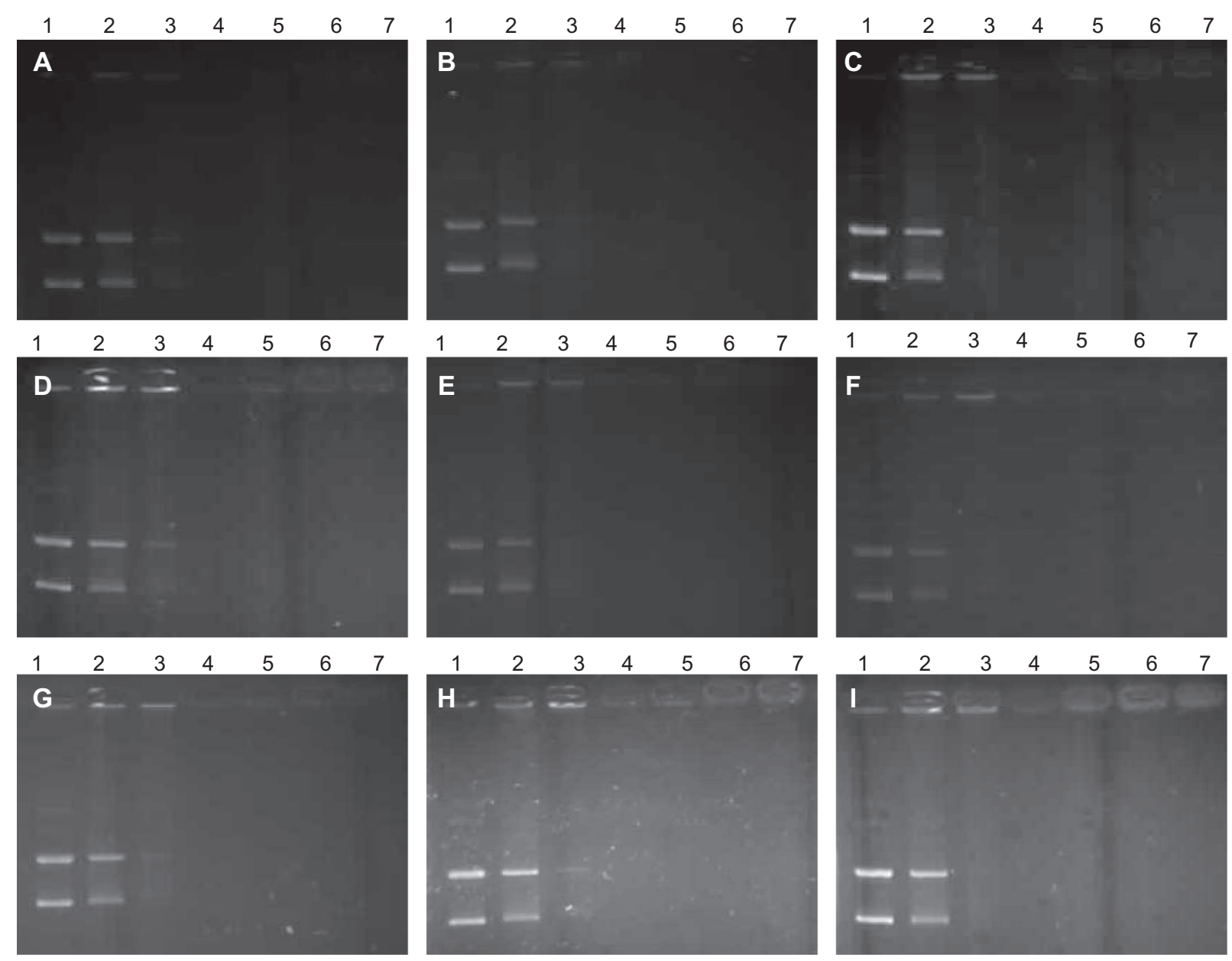

Figure I Gel retarding analysis of PCL/DNA complexes formulated with A) PC/NaO (I0:I), B) PC/NaO (I0:I.5), C) PC/NaO (I0:2), D) PC/CHAPS (I0:I), E) PC/CHAPS (I0:I.5), F) PC/CHAPS (I0:2), G) PC/NaT (I0:I), H) PC/NaT (I0:I.5), and I) PC/NaT (I0:2). Lane I, pEGFP-C2; lanes 2-7, PEI-coated liposomes (PCL)/DNA complexes at weight ratios of $0.05,0.1,0.5, \mathrm{I}, 5$, and 10 , respectively.

Abbreviations: PC, phosphatidylcholine; PCL, polycationic liposomes; PEl, polyethylenimine; $\mathrm{NaO}$, sodium oleate; $\mathrm{NaT}$, sodium taurocholate; CHAPS (3-[\{3-cholamidopropyl\}dimethylammonio]-I-propanesulfonate) (zwitterionic surfactant); pEGFP-C2, plasmid DNA encoding green fluorescent protein.

cytosolic delivery of DNA and PEI for delivery of cytosolic DNA into the nucleus if PEI has the ability to enter into the nucleus in nondividing cells. Alternatively, if PEI cannot pass through the nuclear membrane, PEI still has ability to enhance the interaction of foreign DNA with chromatins during cell division. ${ }^{16,17}$

One of the major requirements for vectors used for gene delivery is low cytotoxicity. Therefore, the cytotoxicity study of the PCL/DNA complex was performed in Huh7 cells. Figure $5 \mathrm{~B}$ shows the effect of carrier/DNA weight ratios $(0.3,0.4,0.5,0.75,0.9,1.0$, and 1.5$)$ on cell viability. When Huh7 cells were incubated with $1 \mu \mathrm{g}$ of naked DNA, cell viability remained almost the same as that seen in nontransfected control cells (data not shown). There was a significant decrease in cell viability when Huh7 cells were incubated with various weight ratios of both PEI/DNA and PCL/DNA complexes. Their average cell viability was decreased when the carrier/DNA weight ratio increased. However, viability was over $80 \%$ for the PCL/DNA complexes. Therefore, in this study, PCL were clearly demonstrated to be safe. This result is similar to that of a previous study by $\mathrm{Hu}$ et $\mathrm{al}^{20}$ who developed an efficient gene delivery system by combining PEI/DNA complexes, anionic liposomes, and a streptavidinmonoclonal antibody. They showed that these lipopolyplexes helped to decrease cytotoxicity. Their in vitro experiment in SMMC-7721 cells showed that lipopolyplexes did not have significant toxicity. In contrast, PEI/DNA markedly reduced cell viability.

Previous studies have reported that the transfection efficiency of lipoplexes and polyplex-associated gene expression was inhibited by serum. Serum was shown to inhibit transfection activity depending on the charge and composition of the complexes. It is already known that anionic compounds present in serum often complex with positively charged 
A
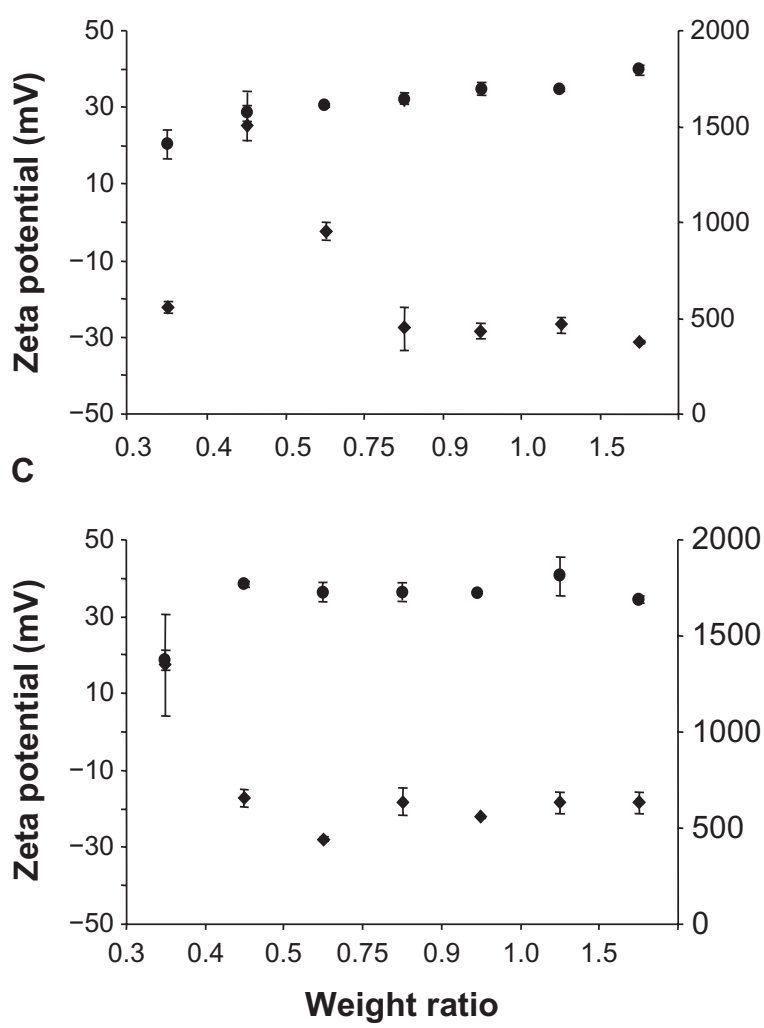

B
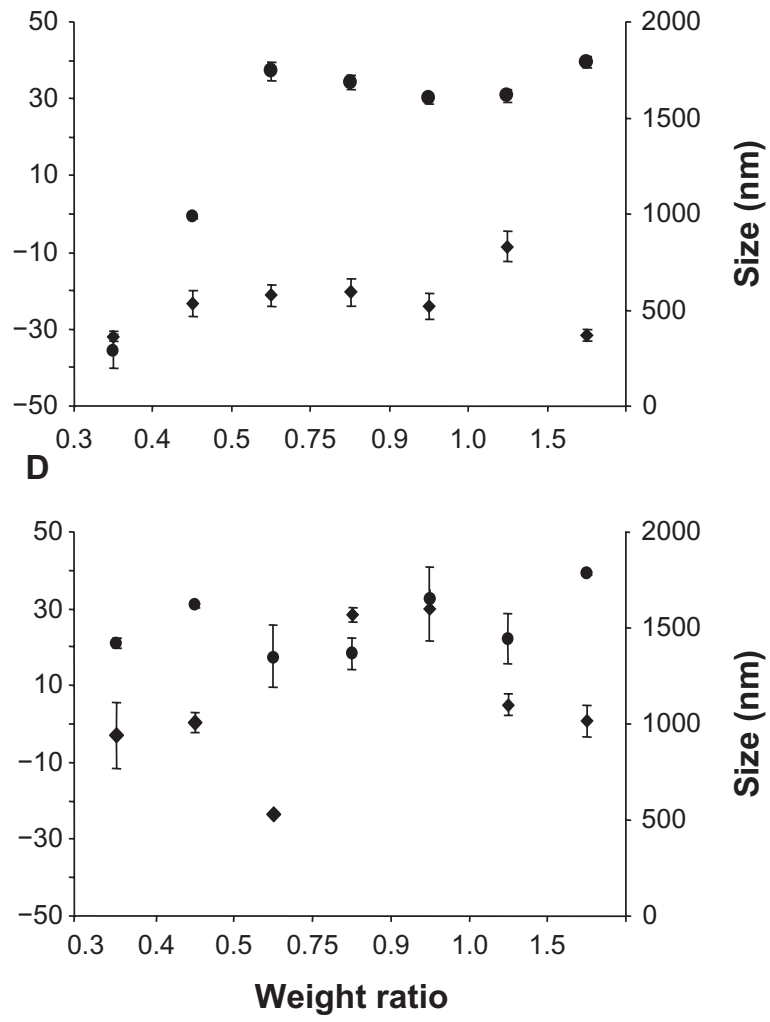

Figure 2 Zeta potential $(\bullet)$ and particle size $(\bullet)$ at varying weight ratios of PCL/DNA complexes formulated with A) PEI, B) PEI-coated PC/NaO (I0:2) liposomes, C) PEl-coated PC/CHAPS (I0:2) liposomes, and D) PEl-coated PC/NaT (I0:2) liposomes.

Note: Each value represents the mean \pm standard deviation of three measurements.

Abbreviations: PC, phosphatidylcholine; PCL, polycationic liposomes; PEl, polyethylenimine; NaO, sodium oleate; NaT, sodium taurocholate; CHAPS (3-[\{3-cholamidopropyl\}dimethylammonio]-I-propanesulfonate) (zwitterionic surfactant).

transfection reagents, resulting in decreased transfection efficiency. ${ }^{21,22}$ These interactions result either in the dissociation of the complexes or in the formation of large aggregates, which, above a certain size limit, may be prevented from being internalized by cells. ${ }^{23}$

As shown in Figure 6, the effect of serum on transfection was dependent on the formulation. Association of gene expression in PCL formulated with three kinds of anionic
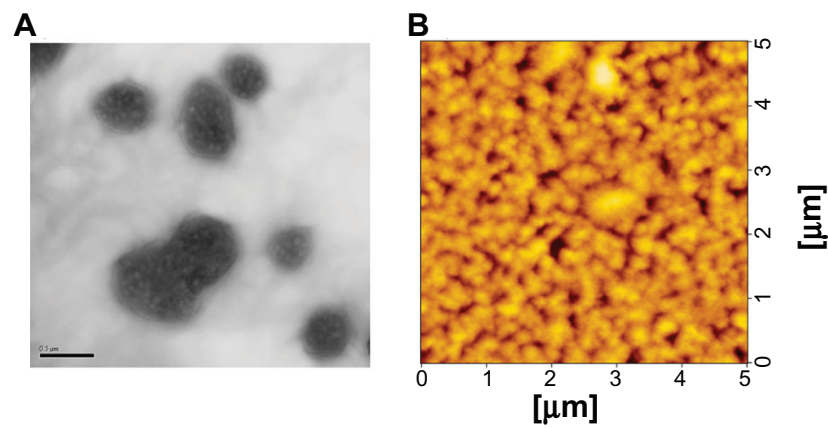

Figure 3 A) Transmission electron microscopic (5000x) images, B) atomic force microscopic images of PEl-coated PC/NaO (10:2) liposomes/DNA complexes at a weight ratio of 0.5 .

Abbreviations: PC, phosphatidylcholine; $\mathrm{PEI}$, polyethylenimine; $\mathrm{NaO}$, sodium oleate. liposomes, ie, $\mathrm{PC} / \mathrm{NaO}$ (10:2), PC/CHAPS (10:2), and $\mathrm{PC} / \mathrm{NaT}(10: 1.5)$, was observed in both the presence and absence of serum. For these experiments, the presence of $10 \%$ serum in the transfection medium of $\mathrm{pH} 7.4$ decreased the transfection efficiency of PCL formulated with $\mathrm{PC} / \mathrm{NaO}$ (10:2) and PC/NaT (10:1.5), while that of PCL formulated with PC/CHAPS (10:2) was not significantly affected by the presence of serum. In this regard, it is reasonable to assume that the significant decrease in transfection activity mediated by complexes prepared from $\mathrm{PC} / \mathrm{NaO}(10: 2)$ and $\mathrm{PC} / \mathrm{NaT}$ $(10: 1.5)$ in the presence of serum resulted from interactions with serum proteins. In the case of PC/CHAPS (10:2), CHAPS is a cholic acid derivative in which the carboxylic acid has been amidated with the zwitterionic aminosulfonic acid moiety. Thus, it retains the same hydrophobic-hydrophilic topology as the rest of the bile salt series except that they are formally neutral. CHAPS have gained widespread use in the solubilization and reconstitution of proteins. The solubilization of membrane proteins is affected by the ionic characteristics and critical micellar concentration of detergents. For the membrane proteins, zwitterionic detergents were less efficient 
A
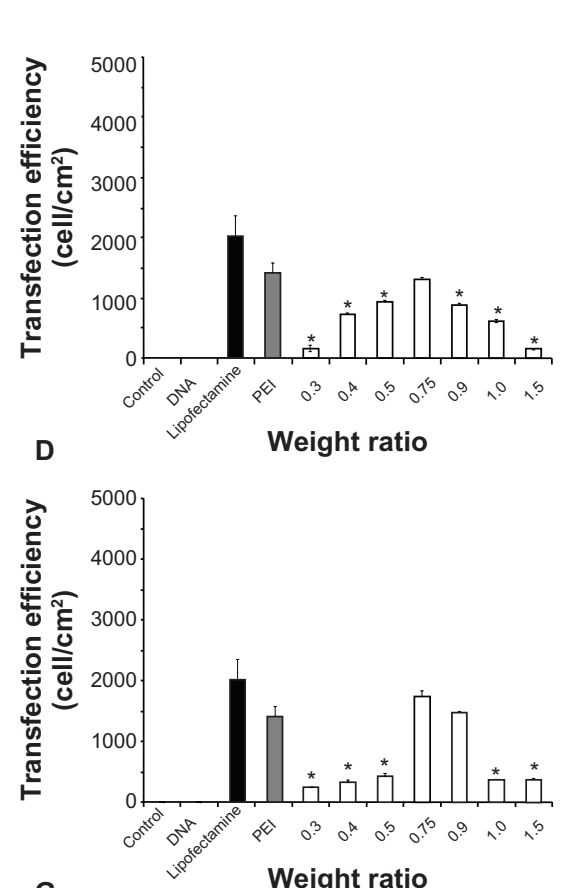

G

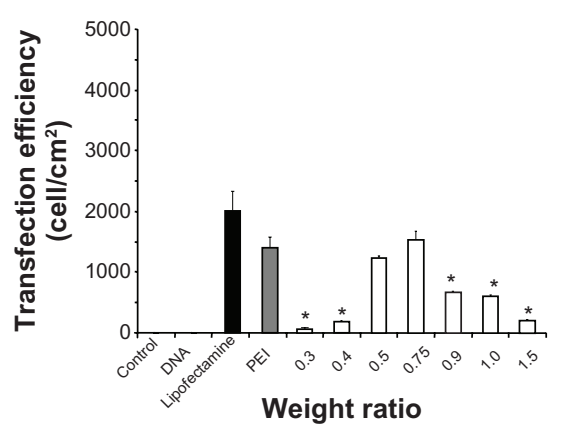

B

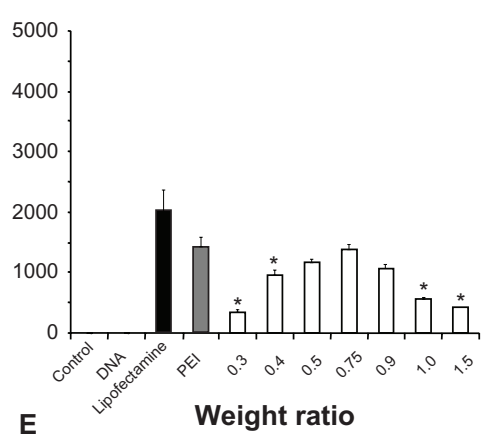

$\mathrm{E}$
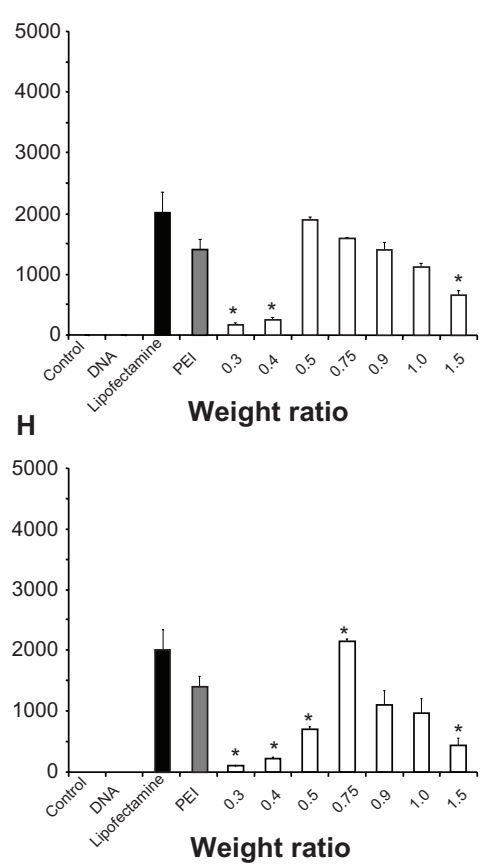

C
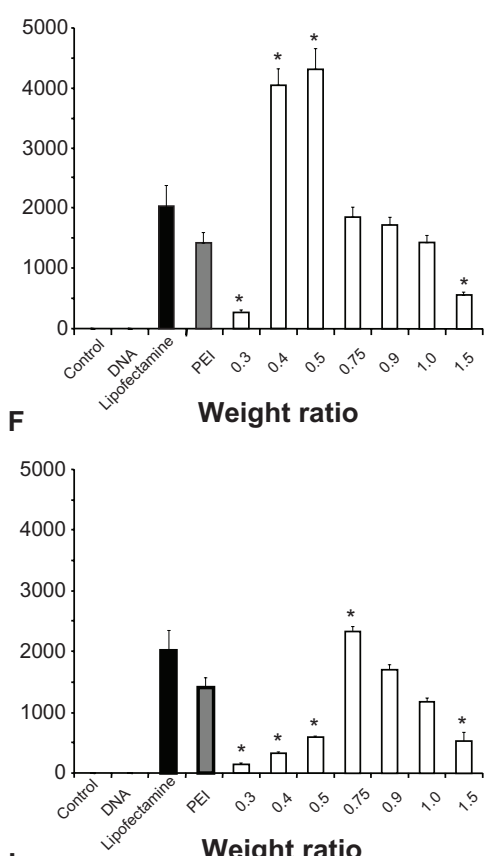

I

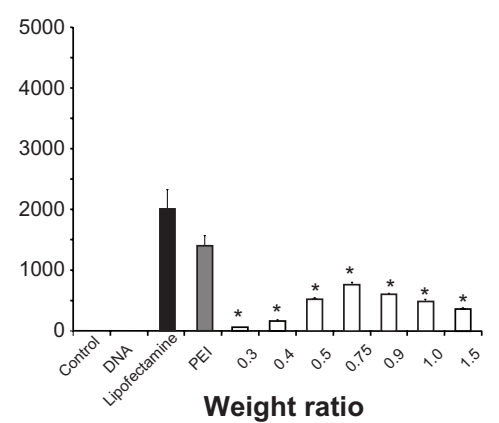

Figure 4 Transfection efficiencies of PCL/DNA complexes formulated with A) PC/NaO (I0:I), B) PC/NaO (I0:I.5), C) PC/NaO (I0:2), D) PC/CHAPS (I0:I), E) PC/CHAPS (I0:I.5), F) PC/CHAPS (I0:2), G) PC/NaT (I0:I), H) PC/NaT (I0:I.5), and I) PC/NaT (I0:2) in Huh7 cells.

Notes: Each value represents the mean \pm standard deviation of three wells. * statistically significant $(P<0.05)$.

Abbreviations: PC, phosphatidylcholine; PCL, polycationic liposomes; PEl, polyethylenimine; $\mathrm{NaO}$, sodium oleate; $\mathrm{NaT}$, sodium taurocholate; CHAPS (3-[\{3-cholamidopropyl\}dimethylammonio]-I-propanesulfonate) (zwitterionic surfactant).

than ionic detergents. ${ }^{24,25}$ Thus, ionic detergents facilitated the incorporation of serum proteins. This observation is consistent with previous reports showing that the formulations containing cholesterol were more active in vivo than those containing dioleoyl phosphatidylethanolamine (DOPE), which has been attributed to their higher stability in biological fluids. This higher stability in the presence of serum is most likely due to the ability of cholesterol to confer membrane stability in contrast with DOPE, which is known to have an inverted cone shape that is associated with membrane fluidity, thus facilitating binding and/or incorporation of serum proteins. ${ }^{26} \mathrm{Oku}$ et al ${ }^{13}$ also reported that, in the presence of serum PCL composed of PC and cetylated PEI (P18C24), there was more enhanced gene transfer than without serum. On the contrary, the efficiency mediated by Dotap liposomes or Lipofectamine was markedly suppressed in the presence of serum. To clarify the reason for serum activation of PCL-mediated transfection, they examined the formation of DNA-PCL complexes under the microscope. PCL and DNA appeared as rather heterogeneous aggregates in the absence of serum, but formed smaller and rather homogeneous ones in the presence of serum. In addition, Marchini et al showed that when serum was added, the transfection efficiency of all lipoplex formulations (didecyldimethylammonium bromide-dioleoylphosphatidylethanolamine and $3 \beta[\mathrm{N}-$ (N',N'-dimethylaminoethane)-carbamoyl] cholesteroldioleoylphosphatidylethanolamine) was found to increase. They identified structural stability and an increase in size in serum as major parameters regulating the efficiency of lipofection. By extrapolation, they proposed that serum, 

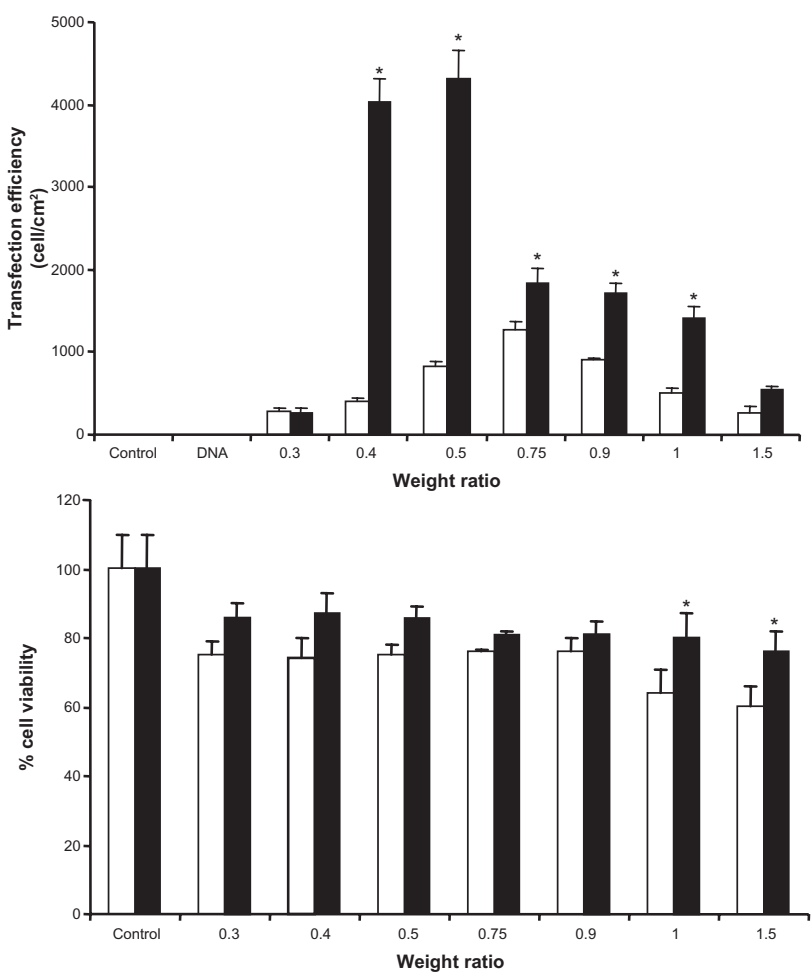

Figure 5 Comparison of the A) transfection efficiencies, B) cell viability of PEI/ DNA ( $\square$ ) and PEl-coated PC/NaO/DNA ( $\square$ ) complexes at various weight ratios in Huh7 cells.

Notes: Each value represents the mean \pm standard deviation of three wells. * statistically significant $(P<0.05)$.

Abbreviations: PC, phosphatidylcholine; PEl, polyethylenimine; $\mathrm{NaO}$, sodium oleate.

regulating the size of resistant lipid-DNA complexes, can control the mechanism of internalization of lipoplexes and, in turn, their efficiency. ${ }^{27}$ Although conflicting reports exist regarding the optimal size of lipoplexes for lipofection, there is no doubt that high lipofection would be gained from large lipoplexes when endocytosis is dominant, because large particles facilitate membrane contact and fusion. When the

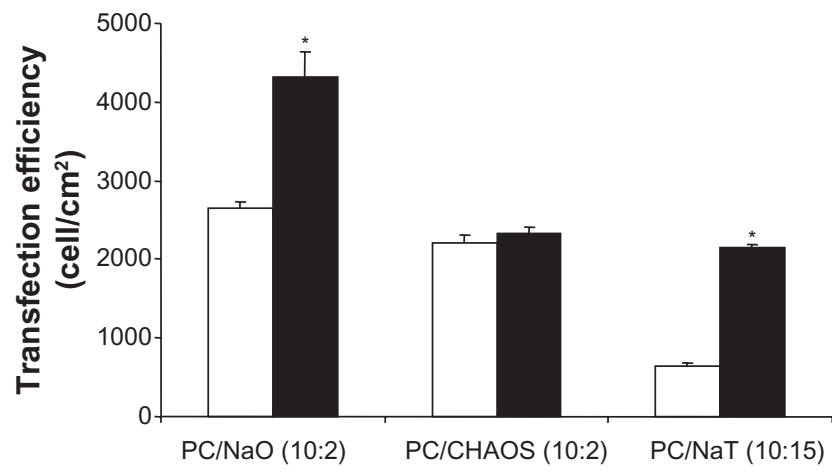

Figure 6 Comparison of the transfection efficiencies of PCL/DNA complexes formulated with PC/NaO (10:2), PC/CHAPS (10:2), and PC/NaT (10:1.5) in Huh7 cells with $10 \%$ serum $(\square)$ and without serum $(\square)$ in the transfection reagent. Note: * statistically significant $(P<0.05)$.

Abbreviations: PC, phosphatidylcholine; PCL, polycationic liposomes; $\mathrm{NaO}$, sodium oleate; NaT, sodium taurocholate; CHAPS (3-[\{3-cholamidopropyl\}dimethylammonio]-I-propanesulfonate) (zwitterionic surfactant). type of cell is not an actively endocytosing cell, either small particles may have high transfection efficiency, or lipoplex size may not correlate with lipofection efficiency. In addition to lipoplex size, different conditions (such as cationic lipids, cell types and in vivo/in vitro) may result in different transfection efficiency. ${ }^{28}$

\section{Conclusion}

In this study, we have developed PEI-coated anionic liposomes as efficient gene carriers. PCL composed of PC: $\mathrm{NaO}$ (10:2) showed superior transfection efficiency with $\mathrm{NaT}$ and CHAPS at all weight ratios tested, while for PC/CHAPS the transfection capability did not alter even in the presence of serum. This study suggests that PCL is safe and exhibits a significantly improved gene delivery capability in vitro. Because both PEI and liposomes can be easily modified with various ligands, these lipopolyplexes might be useful in the design of targeted carriers specific for cell-surface receptors in the delivery of therapeutic genes.

\section{Acknowledgments}

The authors would like to acknowledge the financial support of the Research, Development and Engineering Fund through the National Nanotechnology Center, National Science and Technology Development Agency, Thailand (Project No. NN-B-22-EN3-17-52-10), and Commission of Higher Education (Thailand), The Thailand Research Fund (DBG5180005) through the Golden Jubilee Ph.D. Program (Grant No. PHD/0092/2551), and Silpakorn University Research and Development Institute (SURDI 53/01/37).

\section{Disclosure}

The authors report no conflicts of interest in this work.

\section{References}

1. Liu Y, Liggitt D, Zhong W, Tu G, Gaensler K, Debs R. Cationic liposome-mediated intravenous gene delivery. J Biol Chem. 1995;270: 24864-24870.

2. Gao X, Huang L. Cationic liposome-mediated gene transfer. Gene Ther. 1995;2444:710-722.

3. Liu Y, Mounkes LC, Liggitt HD, et al. Factors influencing the efficiency of cationic liposome-mediated intravenous gene delivery. Nat Biotechnol. 1997;15:167-173.

4. Boussif O, Lezoualc'h F, Zanta MA, et al. A versatile vector for gene and oligonucleotide transfer into cells in culture and in vivo: Polyethylenimine. Proc Natl Acad Sci U SA. 1995;92:7297-7301.

5. Smedt De SC, Demeester J, Hennink WE. Cationic polymer based gene delivery systems. Pharm Res. 2000;17:113-126.

6. Wrobell I, Collins D. Fusion of cationic liposomes with mammalian cells occurs after endocytosis. Biochim Biophys Acta. 1995;1235:296-304.

7. Xu Y, Szoka FC Jr. Mechanism of DNA release from cationic liposome/ DNA complexes used in cell transfection. Biochemistry. 1996;35: 5616-5623. 
8. Felgner JH, Kumar R, Sridhar CN. Enhanced gene delivery and mechanism studies with a novel series of cationic lipid formulations. J Biol Chem. 1994;269:2550-2561.

9. Cortesi R, Esposito E, Menegatti E, Gambari R, Nastruzzi C. Effect of cationic liposome composition on in vitro cytotoxicity and protective effect on carried DNA. Int J Pharm. 1996;139:69-78.

10. Boussif O, Lezoualc'h F, Zanta MA, et al. A versatile vector for gene and oligonucleotide transfer into cells in culture and in vivo: Polyethylenimine. Proc Natl Acad Sci U S A. 1995;92:7297-7301.

11. Godbey WT, Wu KK, Mikos AG. Poly(ethylenimine) and its role in gene delivery. J Control Rel. 1999;60:149-160.

12. Yamazaki Y, Nango M, Matsuura M, Hasegawa Y, Hasegawa M, Oku N. Polycation liposomes, a novel nonviral gene transfer system, constructed from cetylated polyethylenimine. Gene Ther. 2000;7:1148-1155.

13. Oku N, Yamazaki Y, Matsuura M, Sugiyama M, Hasegawa M, Nango M. A novel non-viral gene transfer system, polycation liposomes. Adv Drug Deliv Rev. 2001;52:209-218.

14. Sugiyama M, Matsuura M, Takeuchi Y, Kosaka J, Nango M, Oku N. Possible mechanism of polycation liposome (PCL)-mediated gene transfer. Biochim Biophys Acta. 2004;1660:24-30.

15. Chen JL, Wang H, Gao JQ, Chen HL, Liang WQ. Liposomes modified with polycation used for gene delivery: Preparation, characterization and transfection in vitro. Int J Pharm. 2007;343:255-261.

16. Harashima H, Shinohara Y, Kiwada H. Intracellular control of gene trafficking using liposomes as drug carriers. Eur J Pharm Sci. 2001;13: 85-89.

17. Lampela P, Elomaa M, Ruponen M, Urtti A, Männistö PT, Raasmaja A. Different synergistic roles of small polyethylenimine and Dosper in gene delivery. J Control Rel. 2003;88:173-183.

18. Hanzlíková M, Soininen P, Lampela P, Männistö PT, Raasmaja A. The role of PEI structure and size in the PEI/liposome-mediated synergism of gene transfection. Plasmid. 2009;61:15-21.
19. Lampela P, Soininen P, Urtti A, Männistö PT, Raasmaja A. Synergism in gene delivery by small PEIs and three different nonviral vectors. Int J Pharm. 2004;270:175-184.

20. Hu Y, Li K, Wang L, Yin S, Zhang Z, Zhang Y. Pegylated immuno-lipopolyplexes: A novel non-viral gene delivery system for liver cancer therapy. J Control Rel. 2010;144:75-81.

21. Ghosh YK, Visweswariah SS, Bhattacharya S. Nature of linkage between the cationic headgroup and cholesteryl skeleton controls gene transfection efficiency. FEBS Lett. 2000;473:341-344.

22. Faneca H, Simões S, Pedroso de Lima MC. Evaluation of lipid-based reagents to mediate intracellular gene deliver. Biochim Biophys Acta. 2002; 1567:23-33.

23. Li S, Tseng WC, Stolz DB, Wu SP, Watkins SC, Huang L. Dynamic changes in the characteristics of cationic lipidic vectors after exposure to mouse serum: Implications for intravenous lipofection. Gene Ther. 1999;6:585-594.

24. Daghastanli KR, Ferreira RB, Thedei G Jr, Maggio B, Ciancaglini P. Lipid composition-dependent incorporation of multiple membrane proteins into liposomes. Colloids Surf B Biointerfaces. 2004;36: 127-137.

25. Cladera J, Rigaud JL, Villaverde J, Duñach M. Liposome solubilization and membrane protein reconstitution using Chaps and Chapso. Eur J Biochem. 1997;243:798-804.

26. Audouy S, Molema G, de Leij L, Hoekstra D. Serum as a modulator of lipoplex-mediated gene transfection: Dependence of amphiphile, cell type and complex stability. J Gene Med. 2000;2:465-476.

27. Marchini C, Montani M, Amici A, et al. Structural stability and increase in size rationalize the efficiency of lipoplexes in serum. Langmuir. 2009; 25:3013-3021.

28. Ma B, Zhang S, Jiang H, Zhao B, Lv H. Lipoplex morphologies and their influences on transfection efficiency in gene delivery. J Control Rel. 2007;123:184-194.
International Journal of Nanomedicine

\section{Publish your work in this journal}

The International Journal of Nanomedicine is an international, peerreviewed journal focusing on the application of nanotechnology in diagnostics, therapeutics, and drug delivery systems throughout the biomedical field. This journal is indexed on PubMed Central,

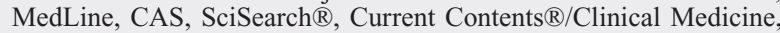

\section{Dovepress}

Journal Citation Reports/Science Edition, EMBase, Scopus and the Elsevier Bibliographic databases. The manuscript management system is completely online and includes a very quick and fair peer-review system, which is all easy to use. Visit http://www.dovepress.com/ testimonials.php to read real quotes from published authors. 